\title{
Metal-Assisted and Microwave-Accelerated Germination
}

Kadir Aslan*, ${ }^{, 1}$, Monet Stevenson ${ }^{1}$, Janelle Guy ${ }^{1}$, Enock Bonyi ${ }^{1}$, Muzaffer Mohammed ${ }^{1}$, Birol Ozturk ${ }^{2}$, Kyle Drake ${ }^{1}$, Freeman McLean ${ }^{1}$ Ashley Souffrant ${ }^{1}$, Amber Bigio ${ }^{1}$

${ }^{1}$ Morgan State University, Department of Civil Engineering, 1700 East Cold Spring Lane,

(1)
Baltimore, MD 21251 USA

${ }^{2}$ Morgan State University, Department of Physics and Engineering Physics, 1700 East Cold Spring Lane, Baltimore, MD 21251 USA

\section{ABSTRACT}

*Corresponding Author: kadir.aslan@morgan.edu

$$
\text { Voice: +1 } 4438852275
$$

ORCID identifier: Kadir Aslan - 0000-0002-7617-0175

We report the proof-of-principle demonstration of a methodology, called Metal-Assisted and Microwave-Accelerated Germination, to modulate the germination of plant seeds and growth of plants using gold nanoparticles (Au NPs) and microwave heating. As a model plant seed, basil seeds were heated in a solution of $20 \mathrm{~nm}$ Au NPs using a microwave waveguide fiber connected to a solid-state microwave operating at $8 \mathrm{GHz}$ at $20 \mathrm{~W}$, which resulted in the development of longer basil gum as observed by optical microscopy. In control experiments, Au NPs or microwave heating was omitted to establish a baseline growth level under standard experimental conditions (no microwave heating or no Au NPs). Our results also show that hydroponic growth and soil growth of basil plants can be delayed with the use of $20 \mathrm{~nm}$ Au NPs at room temperature without microwave heating. The combined use of $20 \mathrm{~nm} \mathrm{Au}$ NPs and microwave heating at 10

Keywords: Plant seeds, basil, germination, gold nanoparticles, microwave heating, plasma treatment of seeds. 


\section{INTRODUCTION}

As humanity continue to face food shortage issues,(Perfecto and Vandermeer, 2010;

34 Clay, 2011; Crist et al., 2017) a number of methods are developed with the aim of greater food 35 production(Townsend and Porder, 2012; Scott et al., 2018; Jacobsen et al., 2019; Tiberius et al., 36 2019). To increase the production of food from plants, their seeds are subjected to a number of 37 physical methods, such as, ultraviolet light treatment,(Noble, 2002) magnetic field 38 treatment,(Maffei, 2014) and hot water soaking,(Hsu et al., 2003) and chemical 39 methods(Farajollahi et al., 2014) with the specific goal of reducing the natural germination times 40 of seeds. The above-mentioned methods are either time-consuming, labor-intensive, or produce 41 harmful by-product; thus, alternative techniques for the acceleration of the plant germination 42 process are being pursued. Recently, emerging techniques, such as, cold plasma treatment,(Ling et al., 2014; de Groot et al., 2018) radio frequency,(Mildažienè et al., 2019) or a combined use of

44 the three(Mildaziene et al., 2016) were developed for the potential rapid germination of plant seeds. Although these techniques enhance the germination process, several limitations including lack of reduction of germination time, inconsistent results, and unsuitable moisture around the seeds hinder their wide-spread application.

In addition, carbon-based and metallic nanoparticles (NPs) have been shown to enhance germination and seedling growth, physiological activities, nitrogen metabolism, mRNA expression and protein expression levels, and a few examples are summarized here. For example, in a study by Kole et. al. (Kole et al., 2013) fullerol was used to treat seeds to evaluate its effect on water uptake and fruit biomass, where an increase of up to $54 \%$ in biomass yield and $24 \%$ in water content was reported. Mahakham et. al. (Mahakham et al., 2017) primed rice seeds with phytosynthesized silver (Ag) NPs improved germination and seedling vigor when compared to an unprimed control, silver nitrate priming, and conventional hydropriming. A key observation of this study is the production of more reactive oxygen species in germinating seeds undergoing nano-priming treatment. Mahakham et. al. (Mahakham et al., 2017) proposed several

58 mechanisms for germinations process, which includes creation of nanopores for water uptake, rebooting of ROS antioxidant systems in seeds, generation of hydroxyl radicals for the loosening

60 of cell wall, and formation of nanocatalyst for starch hydrolysis fastening. Thuesombat et. al. 61 (Thuesombat et al., 2014) investigated the possible effects of different sized Ag NPs (20 nm, 30$6260 \mathrm{~nm}, 70-120 \mathrm{~nm}$, and $150 \mathrm{~nm}$ in diameter) on jasmine rice (Oryza sativa) seed germination and 
63 seedling growth, where Ag NPs $>150 \mathrm{~nm}$ in size were determined to have a more negative effect 64 on rice seedling growth than smaller sizes. Greater permeation of Ag NPs is found in roots when 65 smaller Ag NPs $(<150 \mathrm{~nm})$ are used, yet the smaller Ag NPs were transported to the shoots with 66 less effectively than larger sizes. The use of Ag NPs yields inconsistent and negative results on 67 the growth and development of plants and has the potential to increase environmental toxicity. 68 The shortcomings of existing methods limit ability to accurately and reliably test with sensitivity, 69 specificity, and rapidity. Efforts to address these inadequacies will require innovative techniques 70 capable of rapid germination of seeds.

Our research group has been investigating the effect of combined use of metal NPs and 72 microwave heating on crystallization of amino acids (Pinard and Aslan, 2010) and 73 proteins,(Mauge-Lewis et al., 2015) decrystallization of uric acid crystals,(Thompson et al., 74 2017; Boone-Kukoyi et al., 2019) and biosensors,(Abel et al., 2014; Mohammed et al., 2014). In 75 these studies, metal NPs are either immobilized on a planar surface to assist in the attachment of 76 biological materials through chemisorption (for crystallization (Pinard and Aslan, 2010) and 77 biosensors (Abel et al., 2014; Mohammed et al., 2014)) or in solution to function as "nano78 bullets" in decrystallization of crystals on a planar surface (Thompson et al., 2017; Boone79 Kukoyi et al., 2019). Based on our understanding of combined use of metal NPs and microwave 80 heating to accelerate physical and biological interactions, we hypothesized that the germination 81 of plant seeds and subsequent growth of plants can be modulated by the use of Au NPs and 82 microwave heating.

83 In this proof-of-principle work, we report a methodology to modulate (i.e., delay or 84 accelerate) the germination of basil seeds and subsequent growth of basil plant based on 85 combined use of Au NPs and microwave heating, called Metal-Assisted and Microwave86 Accelerated Germination (MAMAG). The crux of the MAMAG technique is depicted in Figure 87 1. Citrate stabilized (negatively-charged) Au NPs in solution are accelerated by the incident 88 microwave field towards the basil seeds. The increased kinetic energy of the Au NPs increases 89 collisions and interactions between NPs and the basil seeds. Subsequently, the following series 90 of events are thought to occur: the seed testae develop cracks and ridges due to collisions with $91 \mathrm{Au}$ NPs and microwave heating of water contained in the basil seeds (i.e., due to resistive 92 losses), Au NPs bind to enzymes on the seed surface, enzyme activity on the basil seeds are 93 modified by Au NPs and the germination process can be delayed or accelerated based on the 
94 extent of enzyme activity that is directly correlated to the presence of Au NPs and microwave

95 heating. We report that the germination of basil seeds, hydroponic growth and soil growth of

96 basil seeds can be delayed with the use of $20 \mathrm{~nm} \mathrm{Au} \mathrm{NPs} \mathrm{without} \mathrm{microwave} \mathrm{heating} \mathrm{and}$

97 accelerated in combination with microwave heating at up to $20 \mathrm{~W}$ with a solid-state microwave

98 source operating at $8 \mathrm{GHz}$. Since previous reports showed that larger Ag NPs had a negative 99 effect on the growth of plants, we did not attempt to repeat these experiments with Au NPs in our 100 study.

101 MATERIALS and METHODS

Materials. Ocimum basilicum (basil) seeds were purchased from a local seed store in Baltimore, Maryland, USA in 2014 and were kept in cool and dry place until use (i.e., basil seeds were 4 years old at the time of their use in 2018). Citrate-stabilized $20 \mathrm{~nm} \mathrm{Au} \mathrm{NPs} \mathrm{were}$ purchased from Sigma Aldrich (Milwaukee, WI, USA) and stored at $4^{\circ}$ C. 4-Methylumberlliferyl butyrate (product number: 19362-5G) was purchased from Sigma Aldrich (USA) and was used as fluorogenic substrates for esterase. HTS well plates containing 96, flat bottomed wells, was acquired from Sarstedt (Newton, NC, USA, product number: 82.1583.001).

Instrumentation. A Digi-microscope from Digitech Industries, Inc. (USA) was used to

110 view basil seeds during microwave heating using the ISYS800 system (an $8 \mathrm{GHz}$ solid-state 111 microwave source with variable power levels from 0-20 W, from Emblation Ltd (Scotland, UK).

112 Microwave heating of samples is accomplished using a ceramic applicator tip (diameter $=5 \mathrm{~mm})$

113 and a coaxial cable (outer diameter $=6.7 \mathrm{~mm}$ and length $=1.3 \mathrm{~m}$ ) that delivers microwaves from 114 the source to the applicator tip. The natural luminescence of the seeds and the esterase activity 115 was measured using a Cytation ${ }^{\mathrm{TM}} 5$ Cell Imaging Multi-Mode Reader from BioTek Instruments, 116 Inc. (Winooski, VT, USA). Changes in temperature of the seeds during microwave heating were 117 measured using the ETS320 model thermal imaging camera from FLIR ${ }^{\circledR}$ Systems, Inc. 118 (Wilsonville, OR, USA), which was placed directly under the optically clear HTS wells. A 119 Phenom XL PhenomWorld Desktop Scanning Electron Microscope (SEM) equipped with 120 elemental analysis capability (ThermoFisher Scientific, Waltham, MA, USA) was used to image 121 the seeds before and after microwave heating.

122 Micro-seed hydroponic growth pads and pH Perfect Technology Grow nutrient prepared 123 by Advanced Nutrients (Abbotsford, BC, Canada, optimum dilution 1:1000) were utilized in 124 hydroponic studies. The soil used to fill growth pads was obtained Miracle Gro Seed Starting 
125 Potting Mix (EcoGreenText, Inc. NY, USA). The greenhouse (dimensions 120 x 120 x $200 \mathrm{~cm}$ )

126 was purchased from (Amazon.com) and a light source capable of reflecting all light was obtained

127 from Amazon.com. All water used was purified using a Millipore Direct Q3 apparatus.

128 Methods. Determination of seed population viability at room temperature. One hundred

129 basil seeds were completely covered with water in an open top pan at room temperature for 1

130 hour. Then, basil seeds were placed on top of $0.22 \mu \mathrm{m}$ filter paper in a standard circular petri

131 dish. Petri dish was closed with its original lid and were kept in the dark for 4 days during which

132 the germination percentage was calculated daily. The percentage of basil seed germination was

133 calculated using the following equation: ([\# of seeds germinated/total \#of seeds] $\mathrm{x}$ 100) to

134 estimate the viability of the seed population.

Determination of the combined effect of gold nanoparticles and microwave heating on

136 basil seeds. Basil seeds were placed in either $50 \mu \mathrm{L}$ deionized water or $50 \mu \mathrm{L} 20 \mathrm{~nm}$ gold 137 nanoparticles (Au NPs) in a 96-well flat bottom plate. Each well of the HTS plates can hold up to

$138100 \mu \mathrm{L}$ of solvent. Head space in the HTS wells after the addition of solutions to basil seeds was

139 used to allow to help cope with the increase in water vapor pressure and to prevent spillage of

140 water or $20 \mathrm{~nm} \mathrm{Au} \mathrm{NPs} \mathrm{from} \mathrm{the} \mathrm{wells} \mathrm{during} \mathrm{microwave} \mathrm{heating.} \mathrm{Dry} \mathrm{basil} \mathrm{seeds} \mathrm{without}$

141 solution were used as control seeds. All basil seeds (i.e., dry basil seeds, basil seeds in water, and

142 basil seeds in $20 \mathrm{~nm}$ Au NPs) were treated with continuous microwave heating (2 W, $10 \mathrm{~W}, 20$

143 W) for 6 minutes. Before and after microwave heating, brightfield, fluorescent images, and SEM

144 images were obtained to characterize the effect of microwave heating on basil seeds. Fluorescent

145 images were obtained using a DAPI (blue) filter, a GFP (green) filter, and an RFP (red) filter

146 setting of our Cytation 5 Multi-mode Cell Imager. Basil seed gum (mucilage) was characterized

147 by SEM after microwave heating. We also measured temperature changes in the HTS wells with

148 basil seeds during microwave heating using thermal imaging. Control experiments without 149 microwave heating were performed at room temperature.

150 Determination of gold nanoparticles and microwave heating effects on hydroponic

151 growth. We utilized a modified flood and drain hydroponic growth system to determine the 152 combined effect of microwave heating and $20 \mathrm{~nm} \mathrm{Au} \mathrm{NPs} \mathrm{on} \mathrm{hydroponic} \mathrm{growth.} \mathrm{In} \mathrm{our}$ 153 hydroponic growth system, a polypropylene hydroponic growth pad was placed inside a petri 154 dish. Three basil seeds kept in water at room temperature for 6 minutes (control experiment, no 155 microwave heating), basil seeds kept in a solution of $20 \mathrm{~nm} \mathrm{Au} \mathrm{NPs} \mathrm{at} \mathrm{room} \mathrm{temperature} \mathrm{for} 6$ 
156 minutes (no microwave heating), basil seeds in water with continuous microwave heating at 10

$157 \mathrm{~W}$ for 6 minutes, and basil seeds in a solution of $20 \mathrm{~nm} \mathrm{Au} \mathrm{NPs} \mathrm{with} \mathrm{continuous} \mathrm{microwave}$

158 heating at $10 \mathrm{~W}$ for 6 minutes were placed in the hydroponic growth pad. Holes in the

159 hydroponic growth pad were made as same depth as the basil seeds to prevent root entanglement.

160 The hydroponic growth system was well hydrated without evaporation of water throughout basil 161 seed germination process.

162 Determination of gold nanoparticles and microwave heating effects on growth of basil

163 seeds in soil in a greenhouse. Basil seeds were placed in either $50 \mu \mathrm{L}$ deionized water or $50 \mu \mathrm{L}$

164 solution of $20 \mathrm{~nm}$ Au NPs in a 96-well flat bottom plate. All basil seeds (i.e., basil seeds in water 165 and basil seeds in $20 \mathrm{~nm}$ Au NPs) were treated with continuous microwave heating (2 W, $10 \mathrm{~W}$, $16620 \mathrm{~W}$ ) for 6 minutes. After microwave heating, basil seeds were placed in seedling starter trays.

167 Seedling starting trays with basil seeds were placed in a greenhouse with LED light to monitor 168 growth. Basil seeds kept at room temperature and in water at $35^{\circ} \mathrm{C}$ without microwave heating 169 for 6 minutes were used as control seeds. All basil seeds were exposed to LED lighting system 170 (Bloomspect, China, model BS300, $300 \mathrm{~W}$ ) in 8-hour on and off cycles.

171 Thermal Imaging Analysis. A FLIR thermal imaging camera (model ETS320) was used 172 to determine the changes in temperature in the solution containing basil seed during microwave 173 heating and at room temperature (control experiment, no microwave heating). Basil seeds were 174 exposed to the treatment of no solution (dry), water, or $20 \mathrm{~nm} \mathrm{Au} \mathrm{NPs} \mathrm{with} \mathrm{no} \mathrm{microwave}$ 175 treatment or $2 \mathrm{~W}, 10 \mathrm{~W}$, or $20 \mathrm{~W}$ of microwave treatment for 6 minutes while simultaneously 176 recording with the thermal imaging camera. Thermal images were taken every 30 seconds using $177 \quad$ FLIR $^{\circledR}$ Systems software.

178 Scanning Electron Microscopy (SEM). The topography of basil seeds prior to and after 179 exposure to experimental conditions described in the previous section was studied with SEM. 180 Untreated basil seeds were placed on a piece of carbon tape and loaded into a Phenom XL SEM 181 instrument. After focusing and setting the magnification to 300x, an image of the seed was 182 captured. The same basil seeds were then subjected to the treatment of no solution (dry), water, 183 or $20 \mathrm{~nm} \mathrm{Au} \mathrm{NPs} \mathrm{with} \mathrm{no} \mathrm{microwave} \mathrm{heating} \mathrm{or} 2 \mathrm{~W}, 10 \mathrm{~W}$, or $20 \mathrm{~W}$ of microwave heating for 6 184 minutes. The seed was then reloaded into the SEM machine and another image was captured. 185 Elemental analysis on the captured images were carried out to quantify the extent of $20 \mathrm{~nm} \mathrm{Au}$ 186 NPs on the basil seeds. 

2450) was used to measure electrical conductivity of basil seeds soaked either in water or in a solution of $20 \mathrm{~nm}$ Au NPs. Dry basil seeds were used as control experiment. Using the graphic user interphase window of the instrument, basic source measure settings were set as follows; measurement type $=$ ohmmeter, sense $=2$-wire sense, range of resistance $=$ auto, and current source parameters $($ range $=$ auto, source $=1 \mu \mathrm{A}$ and voltage $=21 \mathrm{~V}$ ). The two wire terminals from the source meter were pressed on each side of the seeds and the resistance read-out was recorded. Assuming that the seeds were elliptical in shape, the longer $(1.1 \mathrm{~mm})$ and shorter $(0.11$ $\mathrm{mm}$ ) lengths were measured, and the cross-sectional area determined. Resistivity values were calculated using resistance, area and length measurements. Electrical conductivity was calculated as a reciprocal of resistivity.

(FDTD) Simulations. FDTD electromagnetic simulations were performed to determine the percentage of microwave absorption by each component of the system and to visualize the electric field propagation through the structure. MIT's open source MEEP FDTD software (Oskooi et al., 2010) was utilized for the twodimensional simulations. Dielectric constants of seeds at $8 \mathrm{GHz}$ microwave frequency were used in all simulations.(Gabriel et al., 1996) Basil seeds were modeled as an elliptical object (1.1 mm in length and 0.11 in height) placed in air or water. In the electric field visualization simulations, a monomode $8 \mathrm{GHz}$ microwave radiation was modeled as a fixed frequency continuous source located on the top part of the simulation cell. As in the experiments, the microwave radiation was transmitted to the structure through a $5 \mathrm{~mm}$ diameter waveguide, enabling single mode transmission. The field images depicted the propagation of the microwave radiation through the structure.

Resistive losses within the basil seeds caused by the applied electromagnetic field were 211 predicted using COMSOL software (Boston, MA, USA). In this regard, basil seeds were 212 modeled as a $1.1 \mathrm{~mm}$ diameter round object placed in water (fully immersed) and were placed 213 inside a structure with the size of a high-throughput screening well. A monomode microwave 214 source operating at $8 \mathrm{GHz}$ was placed on top of the well structure to completely cover the well 215 similar to the experimental setup. Resistive losses (in $\mathrm{W} / \mathrm{m}^{3}$ ) within the basil seeds were 216 calculated and is shown in three or twelve slices starting from the bottom of the seeds to the top 217 of the seeds. The number of basil seeds used in FDTD simulations (1, 3, 4, and 10 basil seeds) 
were used to demonstrate the homogeneous heating of all seeds and were similar to that was

219 obtained for a single basil seed.

RESULTS AND DISCUSSION

Determination of Seed Population Viability. To assess and minimize the potential experimental errors in germination due to inherent ability of basil seeds purchased from the

224 vendor and the 4 years of storage, overall viability of basil seeds at room temperature was

225 determined prior to the commencement of all experiments. In this regard, the percentage of viable basil seeds in 100 basil seeds was determined for up to 4 days (4-7 days are required for germination of basil seeds at room temperature). Fifteen percent $(n=15)$ of the basil seeds germinated at day 2. At day 3,85\% $(\mathrm{n}=85)$ of the basil seeds sprouted. Nighty-eight percent $(\mathrm{n}$ $229=98$ ) of the basil seeds germinated within 4 days. and only $2 \%$ of the basil seeds were 230 determined nonviable after the 4-day period (Figure S1, Supporting Information). These 231 results imply that $98 \%$ of the basil seeds used in this study can be germinated and accurate 232 comparison of the differences in basil seed germination due to the experimental parameters can 233 be investigated.

Determination of the combined effect of Au NPs and microwave heating on basil seeds using optical microscopy and scanning electron microscopy. To investigate the effect of using

$23620 \mathrm{~nm}$ Au NPs and microwave heating on the basil seeds as compared to control samples (dry 237 basil seeds and basil seeds in water without 20nm Au NPs/microwave heating), optical 238 microscope images that show the top view of the whole basil seeds were taken before and after 239 microwave heating or at room temperature without microwave heating (control experiment)

240 (Figure 2). In this regard, basil seeds were exposed to the various conditions as described in the 241 experimental section: dry basil seeds (no water, no Au NPs), basil seeds in water, in a solution of $24220 \mathrm{~nm} \mathrm{Au} \mathrm{NPs} \mathrm{were} \mathrm{kept} \mathrm{at} \mathrm{room} \mathrm{temperature} \mathrm{without} \mathrm{microwave} \mathrm{heating} \mathrm{for} 6$ minutes and 243 were exposed to continuous microwave heating at $2 \mathrm{~W}, 10 \mathrm{~W}$ and $20 \mathrm{~W}$ (maximum power of the 244 microwave source at $8 \mathrm{GHz}$ ) for 6 minutes.

245 It is important to discuss the reasons for the selection of experimental conditions prior to 246 the presentation of our observations. The choice for volume of water and $20 \mathrm{~nm} \mathrm{Au} \mathrm{NPs} \mathrm{solution}$ 247 (i.e., $50 \mu \mathrm{L}$ sufficient to fully immerse up to 10 basil seeds) was due to the type of HTS well 248 plates used (96 wells, flat-bottom for easy imaging from the bottom during microwave heating, 
maximum capacity of $100 \mu \mathrm{L}$ ). The choice for the type of metal nanoparticles (Au NPs, diameter

$250=20 \mathrm{~nm}$ ) was due to the following factors: Au NPs are: 1) very stable in water, 2) increase 251 enzyme activity, 3) act as "nano-bullets" in a microwave energy field, 4) easily observed 252 individually under electron microscopy. The continuous microwave heating time of 6 minutes 253 was chosen to minimize the changes to basil seeds in water at room temperature within 6 minutes 254 observed using optical microscopy, therefore, the effect of $20 \mathrm{~nm} \mathrm{Au} \mathrm{NPs} \mathrm{and} \mathrm{microwave}$ 255 heating on basil seeds can be clearly discerned while minimizing the time of exposure of basil 256 seeds to microwave heating. Microwave heating of basil seeds longer than 6 minutes can 257 potentially result in denaturation of enzymes in basil seeds due to increase in seed temperature $258>40^{\circ} \mathrm{C}$ and cause undesired structural damage to plant enzymes and germination process can be 259 negatively affected.

260 Optical Microscopy. Figure 2 shows the overall structural changes to the basil seeds observed using optical microscopy. In a control experiment, which was carried out to demonstrate that water is required to germinate basil seeds and that microwave heating of basil

263 alone in the absence of water do not cause structural damage, no changes in the overall structure

264 of the dry basil seeds was observed after 6 minutes at room temperature without microwave 265 heating or with microwave heating. When kept in water and a solution of $20 \mathrm{~nm} \mathrm{Au} \mathrm{NPs} \mathrm{for} 6$ 266 minutes at room temperature (without microwave heating), basil seeds developed a yellowish 267 gum around the outer layer indicating the commencement of the germination process. Basil seeds 268 kept in a solution of $20 \mathrm{~nm}$ Au NPs without microwave heating for 6 minutes developed longer 269 whitish gum with red tint due to the presence of $20 \mathrm{~nm} \mathrm{Au} \mathrm{NPs} \mathrm{(solution} \mathrm{of} 20 \mathrm{~nm} \mathrm{Au} \mathrm{NPs} \mathrm{is} \mathrm{red}$ 270 in color due their high scattering coefficients above $500 \mathrm{~nm}$ ).

271 Microwave heating of basil seeds in water or in a solution of $20 \mathrm{~nm} \mathrm{Au} \mathrm{NPs} \mathrm{resulted} \mathrm{in}$ 272 the growth of longer gum around the basil seeds. As the microwave power was increased from 2 $273 \mathrm{~W}$ to $20 \mathrm{~W}$, basil seed gum in water appeared to increase in length of and became dense and 274 cloudier, which implies that microwave heating of basil seeds in water alone can increase the 275 germination speed of basil seeds. Microwave heating of basil seeds in a solution of $20 \mathrm{~nm} \mathrm{Au}$ 276 NPs also resulted in the increase in length and change in the color of basil seed gum. These 277 observations implied that Au NPs and microwave heating can be also used in increasing the 278 speed of germination of basil seeds. Since microwave heating of dry basil seeds did not result in 
the growth of basil seed gum, the remainder of the experiments were carried out in water or in a solution of $20 \mathrm{~nm}$ Au NPs.

To investigate whether multiple basil seeds can be germinated at once using microwave heating, 10 basil seeds in water or in the presence of a solution of $20 \mathrm{~nm} \mathrm{Au} \mathrm{NPs} \mathrm{were} \mathrm{placed} \mathrm{in}$ the same HTS wells (basil seeds were distributed at the bottom of the well without overlapping each other) and were exposed to continuous microwave heating at $2 \mathrm{~W}, 10 \mathrm{~W}$ and $20 \mathrm{~W}$ for 6 minutes. In addition, to monitor the structural changes in basil seeds during continuous microwave heating and to ascertain the extent of length of basil seed gum, optical images of basil seeds were captured from the bottom of the HTS wells every minute (Figure S2, Supporting Information). These observations reveal that the length of basil gum increases up to the $4^{\text {th }}$ minute of microwave heating and remains at the same length until the end of the experiment, that is, microwave heating of basil seed for 6 minutes is sufficient to initiate germination of basil

Scanning Electron Microscopy (SEM). In addition to the optical microscopy images of basil seeds after microwave heating in the absence and presence of $20 \mathrm{~nm} \mathrm{Au} \mathrm{NPs}$, extensive investigation of structural changes to the basil gum using SEM and elemental analysis was carried out (Figure 3 and Figures S3-S12, Supporting Information), which provided an evidence for the overall structural changes the basil seeds. Figures S3 shows the overall structural changes in the basil gum before $(\mathrm{t}=0 \mathrm{~min})$ and after each experimental condition $(\mathrm{t}=$ 6 minutes) observed by SEM (images acquired from four sides, top, left, right, bottom, for full view of the seeds). SEM images of dry basil seeds kept at room temperature without microwave

300 heating show that seed surface is unchanged after 6 minutes. After 6 minutes of microwave 301 heating of dry basil seeds, light-colored spots on the surface of seeds appeared due to microwave 302 heating. Basil seeds placed in water without $20 \mathrm{~nm} \mathrm{Au} \mathrm{NPs} \mathrm{at} \mathrm{room} \mathrm{temperature} \mathrm{without}$ 303 microwave heating for 6 minutes developed gum with a small gap on the top and bottom of the 304 seeds. Microwave heating of basil seeds in water without $20 \mathrm{~nm} \mathrm{Au} \mathrm{NPs} \mathrm{for} 6$ minutes resulted

305 in looser gum with large gaps around the seed surface, which indicates that microwave heating 306 alone causes significant changes to basil seeds. Basil seeds placed in a solution of $20 \mathrm{~nm}$ Au NPs 307 at room temperature without microwave heating resulted in observations similar to those 308 observed for basil seeds kept at room temperature for 6 minutes. Microwave heating of basil 309 seeds in a solution of $20 \mathrm{~nm}$ Au NPs for 6 minutes resulted in looser gum with large gaps around 
310 the seed surface. It is important to note that basil seeds were removed from water and the

311 solution of $20 \mathrm{~nm}$ AuNPs to acquire the SEM images, therefore basil gum appears as wrapped

312 around the seed rather than extending into the solution as seen in optical microscopy images.

313 To gain further insight into the structural changes in basil seeds and discern the

314 differences in the basil gum developed around the basil seeds in our experiments, SEM images of

315 the basil gum after each experimental condition (except dry basil seeds, which lacked basil gum)

316 were collected and compared. Figure 3 (also Figure S5 and S9, Supporting Information)

317 show that basil gum appears more spread out in a solution of $20 \mathrm{~nm} \mathrm{Au} \mathrm{NPs} \mathrm{as} \mathrm{compared} \mathrm{to}$ 318 those kept in water. Microwave heating of basil seeds for 6 minutes results in a distribution of 319 basil gum around the basil seeds depending on: 1) the level of microwave power and 2) the 320 absence or presence of $20 \mathrm{~nm} \mathrm{Au} \mathrm{NPs.} \mathrm{Basil} \mathrm{gum} \mathrm{appears} \mathrm{more} \mathrm{spread} \mathrm{out} \mathrm{in} \mathrm{basil} \mathrm{seeds}$ 321 microwave heated as compared to basil gum kept in a solution of $20 \mathrm{~nm}$ AuNPs or water at room 322 temperature without microwave heating. Similar observations are made as the microwave power 323 is increased from $2 \mathrm{~W}$ to $20 \mathrm{~W}$ : basil gum appeared to spread out the most at $20 \mathrm{~W}$, and the 324 presence of $20 \mathrm{~nm}$ Au NPs increases the spreading of the basil gum. The observations discussed 325 in the text so far imply the following: i) basil seeds develop basil gum faster in the presence of $32620 \mathrm{~nm} \mathrm{Au} \mathrm{NPs} \mathrm{and} \mathrm{microwave} \mathrm{heating,} \mathrm{and} \mathrm{can} \mathrm{germinate} \mathrm{faster} \mathrm{due} \mathrm{to} \mathrm{increased} \mathrm{enzyme}$ 327 activity, or ii) basil gum is destroyed due to microwave heating, enzymes are denatured and basil 328 seeds cannot germinate as compared to the control basil seeds (at room temperature, no Au NPs, 329 no microwave heating).

330 In addition, circular structures $c a .5 \mu \mathrm{m}$ in size that are part of the basil gum are seen 331 around the basil seeds kept in water. Although $20 \mathrm{~nm}$ Au NPs are significantly smaller than these 332 circular structures, $20 \mathrm{~nm} \mathrm{Au} \mathrm{NPs} \mathrm{are} \mathrm{brighter} \mathrm{due} \mathrm{to} \mathrm{their} \mathrm{ability} \mathrm{to} \mathrm{scatter} \mathrm{electrons} \mathrm{more}$ 333 efficiently than the seed components. Individual $20 \mathrm{~nm}$ Au NPs are clearly visible and appeared 334 to be distributed along the basil gum without aggregation as seen in SEM images, which can be 335 attributed to the presence of enzymes (and other biological materials) in the basil seed and basil 336 gum. Quantitative elemental analysis of the basil seeds after 6 minutes incubation in a solution of

$33720 \mathrm{~nm} \mathrm{Au} \mathrm{NPs} \mathrm{at} \mathrm{room} \mathrm{temperature} \mathrm{or} \mathrm{microwave} \mathrm{heating} \mathrm{provides} \mathrm{evidence} \mathrm{for} \mathrm{the} \mathrm{spatial}$ 338 distribution of $20 \mathrm{~nm} \mathrm{Au}$ NPs around the basil gum (Figure S5 - S12, Supporting 339 Information). Since enzymes contain primary amine and thiol functional groups, Au NPs can 
340 chemisorb on to the enzymes through these functional groups. The effect of chemisorption of $\mathrm{Au}$

341 NPs on the esterase on the basil seeds is discussed in the Supporting Information.

342 Microwave heating of basil seeds in the presence of a solution containing $20 \mathrm{~nm} \mathrm{Au} \mathrm{NPs}$

343 at $2 \mathrm{~W}, 10 \mathrm{~W}$ and $20 \mathrm{~W}$ resulted in an increase of esterase activity as compared to esterase

344 activity for basil seeds in water (Figure S15, Supporting Information). These observations can

345 be explained within the context of the combined effect of microwave heating on the basil gum

346 and $\mathrm{Au}$ NPs-catalyzed esterase activity. (Deka et al., 2012; Arsalan and Younus, 2018) As

347 discussed in the previous paragraphs, microwave heating of basil seeds causes the basil gum to

348 be looser as the microwave power is increased from $2 \mathrm{~W}$ to $20 \mathrm{~W}$, and enzymatic activity is

349 increased due to the availability of esterase around basil seed. In addition, microwave heating of

350 basil seeds in the presence of $20 \mathrm{~nm}$ Au NPs changes the movement and distribution of $20 \mathrm{~nm}$

$351 \mathrm{Au}$ NPs around the basil gum, which in turn can affect the extent of interactions of $20 \mathrm{~nm} \mathrm{Au}$

352 NPs with esterase in the basil gum. Our research group has previously shown that microwave

353 heating of Au NPs in solution increases the diffusivity of Au NPs due to selective heating of

354 water molecules in bulk and around the Au NPs.(Aslan and Geddes, 2007) Since the size of 20

$355 \mathrm{~nm} \mathrm{Au}$ NPs is $c a .1 .88 \times 10^{8}$ times smaller than the wavelength of microwaves at $8 \mathrm{GHz}(3.75 \mathrm{~cm})$

356 and the $20 \mathrm{~nm} \mathrm{Au} \mathrm{NPs} \mathrm{are} \mathrm{negatively} \mathrm{charged,} 20 \mathrm{~nm}$ Au NPs are moved within microwave field

357 without absorbing the microwave energy, while the temperature of water molecules around 20

$358 \mathrm{~nm} \mathrm{Au} \mathrm{NPs} \mathrm{and} \mathrm{in} \mathrm{bulk} \mathrm{is} \mathrm{increased} \mathrm{due} \mathrm{to} \mathrm{molecular} \mathrm{friction,} \mathrm{and} \mathrm{subsequently,} \mathrm{water} \mathrm{is}$

359 selectively heated. As a result of selective heating of water and coupling of negatively-charged

$36020 \mathrm{~nm} \mathrm{Au}$ NPs with electromagnetic field, $20 \mathrm{~nm}$ Au NPs move about the basil seed faster and

361 chemisorption events between $20 \mathrm{~nm} \mathrm{Au} \mathrm{NPs} \mathrm{and} \mathrm{esterase} \mathrm{are} \mathrm{accelerated,} \mathrm{which} \mathrm{affects} \mathrm{the}$

362 distribution of Au NPs on the basil gum.

363 In this regard, the extent of temperature changes in bulk during microwave heating of

364 basil seeds in water and $20 \mathrm{~nm} \mathrm{Au} \mathrm{NPs} \mathrm{solutions} \mathrm{for} 6$ minutes and subsequent cooling period of

$36520 \mathrm{~min}$ taken to monitor enzymatic reactions was measured (Figure S17, Supporting

366 Information). A maximum increase of $c a .11^{\circ} \mathrm{C}$ in temperature from room temperature $\left(25^{\circ} \mathrm{C}\right)$

367 to $36^{\circ} \mathrm{C}$ was observed during microwave heating of basil seeds in water at $20 \mathrm{~W}$. Microwave

368 heating of basil seeds in a solution of $20 \mathrm{~nm}$ Au NPs at $20 \mathrm{~W}$ resulted in increase of temperature

369 from room temperature to $34^{\circ} \mathrm{C}$. Microwave heating of basil seeds in all solutions at $2 \mathrm{~W}$ and 10

$370 \mathrm{~W}$ yielded high temperature in the range of $27^{\circ} \mathrm{C}-30^{\circ} \mathrm{C}$, respectively. These observations imply 
371 that solutions are incrementally heated for 6 minutes below $37^{\circ} \mathrm{C}$, where enzymes are not 372 expected to denature due to microwave heating.

373 It is important to note that our experimental setup (Figure S1, Supporting Information)

374 lacked the ability of simultaneous measurement of temperature (using a FLIR thermal camera) 375 and enzyme activity (using a luminescence imaging instrument) during microwave heating of 376 basil seeds. Therefore, enzymatic activity measurements were carried out immediately after 6 377 minutes of microwave heating of basil seeds for an additional 20 minutes. In addition, changes in 378 temperature of solution after microwave heating was stopped for additional 20 minutes was 379 measured to simulate the experimental conditions during enzymatic activity measurements. The 380 temperature of all solutions returned to their initial values within 10 minutes. It is also important 381 to note that after microwave heating for 6 minutes basil seeds were mixed with an equal volume 382 of substrate solution kept at room temperature or directly transferred to a filter paper for 383 hydroponic growth. The temperature of basil seeds returned to room temperature within 2 384 minutes after microwave heating and temperature does not affect enzyme activity after 385 microwave heating was stopped. Therefore, we can conclude that esterase activity on basil seeds 386 is affected mainly by microwave heating alone and microwave heating in the presence of $20 \mathrm{~nm}$ 387 Au NPs for 6 minutes. Subsequently, microwave heating of basil seeds at $10 \mathrm{~W}$ was selected for 388 hydroponic growth and soil growth experiments based on the following observations: i) 389 temperature of the solution with basil seeds reaches a maximum value of $30^{\circ} \mathrm{C}$ when microwave 390 heated at $10 \mathrm{~W}$ and ii) esterase activity can be modulated by using $20 \mathrm{~nm}$ Au NPs.

Finite-Difference Time-Domain (FDTD) simulations and electrical conductivity

392 measurements for basil seeds. In addition to experimental work to determine the effects of 393 microwave heating of basil seeds, computational simulations were carried out to determine the 394 percentage of microwave absorption by each component of the basil seed/water system and to 395 visualize the electric field propagation through the system. Figure S18 (Supporting 396 Information) shows the simulated electric field distribution around basil seeds with and without 397 water (dry) exposed to monomode microwave point source operating at $8 \mathrm{GHz}$ and $10 \mathrm{~W}$. These 398 simulations show that basil seeds in bulk water is predicted to absorb $9.1 \%$ of the homogenous 399 electromagnetic energy. Conversely, dry basil seeds (no bulk water) are predicted to absorb a $400 \quad 0.7 \%$ extent of the electromagnetic energy due to the presence of water in basil seeds. The 
401 electric field propagation images also imply that the energy is absorbed by the basil seeds submerged in water, while the dry seeds transmit most of the incoming radiation.

To gain further insight to microwave heating of basil seeds through computational 404 simulations of resistive losses of basil seeds (1, 3, 4, and 10 seeds) were carried out (Figures 4 405 and S19-S20, Supporting Information). Figure 4 shows the simulated resistive losses in terms 406 of 12 cross-sections (in the xz-plane and y-direction) from four basil seeds in water exposed to 407 monomode microwave point source operating at $8 \mathrm{GHz}$ and $10 \mathrm{~W}$ using COMSOL software. 408 Resistive losses are predicted to be similar for all four seeds and vary throughout all cross409 sections of an individual basil seed. Since the microwave source is placed on top of the cavity, 410 resistive losses from the top sections (slices 9-12) of the basil seeds are predicted to be the 411 largest and the least resistive losses are predicted from the bottom sections (slices 1-4) of the 412 basil seeds, while middle sections (slices 5-8) of the basil seeds show similar resistive losses. In 413 addition, resistive losses from the top sections of the four basil seeds show the largest extent of 414 losses occur from the sides of the basil seeds facing each other. In the middle and bottom 415 sections of the basil seeds, resistive losses occur from the edges and opposite sides of basil seeds, 416 respectively, which implies that the entire basil seed is heated. Therefore, basil gum is expected 417 to develop from all sides of the basil seeds. Based on these computational simulations, resistive 418 losses for a single seed, three seeds and ten seeds during microwave heating were also calculated 419 (Figures S19-S20, Supporting Information), which predict similar patterns for resistive losses 420 as described for four basil seeds.

421 In addition to theoretical calculations, to further our understanding of the effect of 422 microwave heating on basil seeds, electrical conductivity of basil seeds immersed in water and in 423 a solution of $20 \mathrm{~nm}$ Au NPs for 6 minutes was measured to be: $0.140 \mathrm{~S} /(\mathrm{cm} . \mathrm{g})$ for basil seeds in 424 water and $0.156 \mathrm{~S} /(\mathrm{cm} . \mathrm{g})$ for basil seeds in $20 \mathrm{~nm} \mathrm{Au} \mathrm{NPs.} \mathrm{Since} \mathrm{the} \mathrm{resistivity} \mathrm{of} \mathrm{dry} \mathrm{basil} \mathrm{is}$ 425 extremely high, no electrical conductivity values were measured. These experimental 426 measurements show that basil seeds in water and in a solution of $20 \mathrm{~nm} \mathrm{Au} \mathrm{NPs} \mathrm{have} \mathrm{finite}$ 427 electrical conductivity, and electrical component of microwave energy can couple to the basil 428 seeds and be converted into heat through resistive losses in the basil seeds. Since the bulk 429 temperature of solutions containing basil seeds only reach a maximum value of $30^{\circ} \mathrm{C}$ when 430 microwave heated at $10 \mathrm{~W}$, we can conclude that the development of basil gum is accelerated 431 due to bulk heating and resistive losses in the seeds while enzyme activity is maintained. In the 
432 absence of microwave heating, development of basil gum in water is slower at room temperature,

433 as shown in optical images in this study.

Effect of gold nanoparticles and microwave heating on hydroponic growth of basil

seeds. Based on our ability to control the development of basil gum using $20 \mathrm{~nm} \mathrm{Au} \mathrm{NPs} \mathrm{and}$

436 microwave heating as described above, we investigated the effect of $20 \mathrm{~nm} \mathrm{Au} \mathrm{NPs} \mathrm{and}$

437 microwave heating on hydroponic growth of basil seeds to answer the question of "Can the use

438 of $20 \mathrm{~nm} \mathrm{Au} \mathrm{NPs}$ and microwave heating result in modulation of hydroponic growth of basil

439 seeds?". In this regard, basil seeds immersed in water or in a solution $20 \mathrm{~nm}$ Au NPs were

440 microwave heated at $10 \mathrm{~W}$ for 6 minutes and placed in a hydroponic growth setup as described

441 in the experimental section of this study. In addition, control experiments, where basil seeds

442 were kept at room temperature without microwave heating in water and a solution of $20 \mathrm{~nm} \mathrm{Au}$

443 NPs, were also carried out to discern the differences in using microwave heating versus basil

444 seed growth at room temperature without microwave heating.

445 To establish a reference point for the hydroponic growth experiments with microwave

446 heating treated basil seeds, we first discuss hydroponic growth from basil seeds kept at room

447 temperature without microwave heating. Figure 5 (see also Figure S21, Supporting

448 Information), shows that basil seeds kept in water at room temperature for 6 minutes (i.e.

449 control sample) developed long stems at 72 hours and grow to full reference length with leaves at

450128 hours. At 72 hours, basil seeds kept in a solution of $20 \mathrm{~nm} \mathrm{Au} \mathrm{NPs} \mathrm{at} \mathrm{room} \mathrm{temperature}$

451 grew shorter stem as compared to control sample, which implies that the development of basil

452 plant is delayed in the presence of $20 \mathrm{~nm} \mathrm{Au} \mathrm{NPs.} \mathrm{At} 72$ hours, basil seeds exposed to

453 microwave heating in the presence of $20 \mathrm{~nm} \mathrm{Au} \mathrm{NPs} \mathrm{(i.e.,} \mathrm{sample} \mathrm{labeled} \mathrm{as} \mathrm{MAMAG)}$

454 developed longer stem and leaves as compared to the other samples, which implies that the

455 development of basil plant is accelerated with the combined use of $20 \mathrm{~nm} \mathrm{Au} \mathrm{NPs} \mathrm{and}$

456 microwave heating. At 128 hours, basil plants grown from basil seeds treated with the MAMAG

457 technique (i.e., combined used of Au NPs and microwave heating) displayed the largest leaves

458 and longest stem, while the growth of basil plants grown from basil seeds kept in the solution of

$45920 \mathrm{~nm}$ Au NPs remained delayed and the control sample reached its peak value in stem length

460 and leaf size. At 224 hours, two of the three basil plants grown from basil seeds treated with the

461 MAMAG technique were still viable without any sign of deterioration of leaves or the plant

462 stem. At 224 hours, control sample showed significant deterioration of leaves and the plant stem 
463 and one of the three basil plants grown from basil seeds kept in the solution of $20 \mathrm{~nm}$ Au NPs

464 remained viable. At the end of our observations of basil plant growth at 328 hours, all basil

465 plants deteriorated completely. These observations clearly demonstrated that the hydroponic

466 growth of basil plants can be delayed with the use of $20 \mathrm{~nm}$ Au NPs without microwave heating

467 and accelerated and extended with the combined use of $20 \mathrm{~nm}$ Au NPs and microwave heating.

Effect of gold nanoparticles and microwave heating on growth of basil seeds in soil. In

469 the final step of this study, we investigated the effect of $20 \mathrm{~nm}$ Au NPs alone and combined with

470 microwave heating on the growth of basil seeds to find out whether the growth of basil seeds in

471 soil can be delayed or accelerated on demand. In this regard, after incubation for 6 minutes at

472 room temperature in water or $20 \mathrm{~nm} \mathrm{Au} \mathrm{NPs}$ or in $20 \mathrm{~nm} \mathrm{Au}$ NPs with microwave heating (at 2

$473 \mathrm{~W}, 10 \mathrm{~W}$, and $20 \mathrm{~W}$ ), basil seeds were placed in seedling starter trays to monitor growth in soil

474 for up to 73 days in identical conditions. After 5 days of planting, basil seeds kept in water at

475 room temperature for 6 minutes (i.e., no microwave heating) developed two-leaves, which was

476 used as a reference point (control sample) for the growth of basil seeds in the presence of $20 \mathrm{~nm}$

$477 \mathrm{Au}$ NPs and microwave heating (Figure 6). Basil seeds kept in in $20 \mathrm{~nm} \mathrm{Au} \mathrm{NPs}$ at room

478 temperature without microwave heating developed smaller leaves and the height of the basil

479 plants were shorter than those observed for the control sample, which implied that the growth of

480 basil plants from their seeds treated with $20 \mathrm{~nm} \mathrm{Au} \mathrm{NPs} \mathrm{at} \mathrm{room} \mathrm{temperature} \mathrm{was} \mathrm{delayed} \mathrm{in} \mathrm{soil.}$

481 Microwave heating of basil seeds (at $2 \mathrm{~W}, 10 \mathrm{~W}$, and $20 \mathrm{~W}$ ) in the presence of $20 \mathrm{~nm}$ Au NPs for

4826 minutes resulted in taller basil plants with wider leaves after 5 days of planting in soil, which

483 implied that the growth of basil plants from their seeds microwave heated in the presence of Au

484 NPs was accelerated in soil. Furthermore, after 73 days planting of basil seeds, significant

485 differences between basil plants were observed: while basil plants grown from basil seeds kept in

486 water at room temperature (i.e., no microwave heating) for 6 minutes wilted, basil plants grown

487 from basil seeds kept in a solution of $20 \mathrm{~nm}$ Au NPs at room temperature and basil seeds

488 microwave heated in a solution of $20 \mathrm{~nm} \mathrm{Au} \mathrm{NPs} \mathrm{were} \mathrm{still} \mathrm{thriving} 73$ days after planting in soil

489 (Figure 6). It is important to note all basil plants were exposed to identical experimental

490 conditions. Moreover, the height of the basil plants grown from basil seeds kept in a solution of

$49120 \mathrm{~nm} \mathrm{Au} \mathrm{NPs} \mathrm{at} \mathrm{room} \mathrm{temperature} \mathrm{were} \mathrm{taller} \mathrm{than} \mathrm{any} \mathrm{basil} \mathrm{plant} \mathrm{grown} \mathrm{under} \mathrm{other}$

492 conditions. 
Since microwave heating of basil seeds in water and in $20 \mathrm{~nm} \mathrm{Au} \mathrm{NPs} \mathrm{results} \mathrm{in} \mathrm{an}$

494 increase in temperature up to $36^{\circ} \mathrm{C}$, we investigated the effect of incubation of basil seeds in pre-

495 heated water without microwave heating to compare these results with the results obtained using

496 basil seeds treated with microwave heating. Figures S22 (Supporting Information) show that

497 the development of basil gum, enzymatic activity and soil growth in 17 days were similar to the

498 results observed for basil seeds kept at room temperature without microwave heating, and the

499 MAMAG technique, based on combined use of microwave heating and $20 \mathrm{~nm} \mathrm{Au} \mathrm{NPs,} \mathrm{for} \mathrm{the}$

500 pre-treatment of basil seeds offer a superior alternative to simply soaking basil seeds in pre-

501 heated water. These observations imply that the growth of basil seeds in soil can be delayed or

502 accelerated on demand with $20 \mathrm{~nm}$ Au NPs and microwave heating.

503

504 CONCLUSIONS

505 In this work, we demonstrated that a solution of $20 \mathrm{~nm} \mathrm{Au} \mathrm{NPs} \mathrm{and} \mathrm{microwave} \mathrm{heating}$ 506 from a monomode microwave source can be used as new approach to modulate the germination

507 of basil seeds and subsequent hydroponic growth and soil growth of basil plants. In this regard,

508 single basil seeds or 10 basil seeds were placed in a $50 \mu \mathrm{L}$ solution of $20 \mathrm{~nm} \mathrm{Au} \mathrm{NPs} \mathrm{in} \mathrm{a} \mathrm{HTS}$ 509 well plates and were exposed to 6 minutes of continuous microwave heating using a solid-state 8

$510 \mathrm{GHz}$ microwave generator operating at $2 \mathrm{~W}, 10 \mathrm{~W}$ and $20 \mathrm{~W}$ microwave power. In control 511 experiments, either $20 \mathrm{~nm} \mathrm{Au} \mathrm{NPs}$ or microwave heating was omitted to determine the effect of 512 each of $20 \mathrm{~nm} \mathrm{Au} \mathrm{NPs} \mathrm{alone} \mathrm{(at} \mathrm{room} \mathrm{temperature} \mathrm{without} \mathrm{microwave} \mathrm{heating)} \mathrm{or} \mathrm{microwave}$ 513 heating alone (in water without $20 \mathrm{~nm} \mathrm{Au} \mathrm{NPs).} \mathrm{We} \mathrm{have} \mathrm{made} \mathrm{the} \mathrm{following} \mathrm{conclusions} \mathrm{from}$ 514 our experimental observations and computational simulations:

515 1) Optical microscopy was used to assess the macro-scale changes in basil seeds and showed 516 that

517 a. dry basil seeds did not germinate with or without microwave heating, and

518 b. basil in water or in a solution of $20 \mathrm{~nm} \mathrm{Au}$ NPs in the presence of microwave heating 519 resulted in longer basil gum as compared to basil seeds kept in room temperature without 520 microwave heating.

521 2) SEM was used to assess the micro-scale changes in basil seed gum and showed that 
a. basil seed gum is more spread out due to microwave heating and in the presence of $20 \mathrm{~nm}$ Au NPs, and

b. $20 \mathrm{~nm} \mathrm{Au} \mathrm{NPs} \mathrm{are} \mathrm{distributed} \mathrm{throughout} \mathrm{the} \mathrm{surface} \mathrm{of} \mathrm{the} \mathrm{basil} \mathrm{seeds} \mathrm{without}$ significant aggregation.

3) Luminescence kinetic analysis of enzymatic activity was used to assess the effect of $20 \mathrm{~nm}$ $\mathrm{Au}$ NPs and microwave heating on esterase, which is a key enzyme for germination of basil seeds. Esterase activity was monitored for an additional 20 minutes after the initial 6 minutes incubation of basil seeds,

a. esterase activity in basil seeds in water and in a solution of $20 \mathrm{~nm} \mathrm{Au} \mathrm{NPs} \mathrm{without}$ microwave heating was similar, and

b. esterase activity in basil seeds in $20 \mathrm{~nm}$ Au NPs was up to 2-fold higher than esterase activity in water with microwave heating.

534 4) Maximum actual average temperature of water and $20 \mathrm{~nm}$ Au NPs containing basil seeds during microwave heating at $20 \mathrm{~W}$ was measured to be $36^{\circ} \mathrm{C}$ and $34^{\circ} \mathrm{C}$, respectively. Enzymes in basil seeds are not expected to denature due to microwave heating of basil seeds in water and in a solution of $20 \mathrm{~nm}$ Au NPs.

5) FDTD simulations predict that

a. basil seeds in water absorbs $9.1 \%$, transmits $85.4 \%$, and reflects $5.5 \%$ of the microwave radiation.

6) Hydroponic growth of basil plants can be

a. delayed with the use of $20 \mathrm{~nm} \mathrm{Au} \mathrm{NPs} \mathrm{at} \mathrm{room} \mathrm{temperature} \mathrm{without} \mathrm{microwave} \mathrm{heating,}$

b. Resistive losses from the top sections of the basil seeds show the largest extent of losses occur from the sides of the basil seeds facing each other. Resistive losses occur from the edges and opposite sides of basil seeds in the middle and bottom sections of the basil or

b. accelerated and life of the basil plant can be extended with the combined use of $20 \mathrm{~nm}$ $\mathrm{Au}$ NPs and microwave heating.
7) Growth of basil seeds in soil can be 
a. delayed by pre-treatment of basil seeds in a solution of $20 \mathrm{~nm}$ Au NPs, or

b. accelerated after pre-treatment of basil seeds with microwave heating and a solution of 20 nm Au NPs.

\section{ACKNOWLEDGMENTS}

557 Authors greatly appreciate partial financial support from Morgan State University Innovation 558 Works I-GAP Program.

\section{SUPPORTING INFORMATION}

560 Additional SEM images, luminescence microscopy images of basil seeds, detailed hydroponic growth results, real-time temperature measurements of the well with a single basil seed at room temperature and FDTD simulation of resistive losses are presented.

\section{REFERENCES}

564 Abel, B., Clement, T.C., Aslan, K., 2014. Enhancement of enzymatic colorimetric response by silver island films on high throughput screening microplates. J Immunol Methods 411, 4349.

Arsalan, A., Younus, H., 2018. Enzymes and nanoparticles: Modulation of enzymatic activity via nanoparticles. International Journal of Biological Macromolecules 118, 1833-1847.

Aslan, K., Geddes, C.D., 2007. Microwave-Accelerated Ultrafast Nanoparticle Aggregation Assays Using Gold Colloids. Analytical Chemistry 79, 2131-2136.

Boone-Kukoyi, Z., Moody, K., Nwawulu, C., Ariori, R., Ajifa, H., Guy, J.A., Lansiquot, C., Ozturk, B., McLemore, G.L., Bonyi, E., Aslan, K., 2019. Metal-Assisted and MicrowaveAccelerated Decrystallization of Pseudo-Tophus in Synthetic Human Joint Models. ACS Omega 4, 4417-4428.

de Groot, G.J.J.B., Hundt, A., Murphy, A.B., Bange, M.P., Mai-Prochnow, A., 2018. Cold

Clay, J., 2011. Freeze the footprint of food. Nature 475, 287.

580 Deka, J., Paul, A., Chattopadhyay, A., 2012. Modulating enzymatic activity in the presence of gold nanoparticles. RSC Advances 2, 4736-4745. 
Farajollahi, A., Gholinejad, B., Jonaidi Jafari, H., 2014. Effects of Different Treatments on Seed Germination Improvement of Calotropis persica. Advances in Agriculture 2014, 5.

Gabriel, S., Lau, R.W., Gabriel, C., 1996. The dielectric properties of biological tissues: II.

Measurements in the frequency range $10 \mathrm{~Hz}$ to $20 \mathrm{GHz}$. Phys Med Biol 41, 2251-2269.

Hsu, C.C., Chen, C.L., Chen, J.J., Sung, J.M., 2003. Accelerated aging-enhanced lipid peroxidation in bitter gourd seeds and effects of priming and hot water soaking treatments. Scientia Horticulturae 98, 201-212.

Jacobsen, C., Sørensen, A.-D.M., Holdt, S.L., Akoh, C.C., Hermund, D.B., 2019. Source, Extraction, Characterization, and Applications of Novel Antioxidants from Seaweed. Annual Review of Food Science and Technology 10, 541-568.

Kole, C., Kole, P., Randunu, K.M., Choudhary, P., Podila, R., Ke, P.C., Rao, A.M., Marcus,

Maffei, M.E., 2014. Magnetic field effects on plant growth, development, and evolution. Frontiers in Plant Science 5.

Mahakham, W., Sarmah, A.K., Maensiri, S., Theerakulpisut, P., 2017. Nanopriming technology for enhancing germination and starch metabolism of aged rice seeds using phytosynthesized silver nanoparticles. Sci Rep 7, 8263-8263.

Mauge-Lewis, K., Mojibola, A., Toth, E.A., Mohammed, M., Seifu, D., Aslan, K., 2015. MetalAssisted and Microwave-Accelerated Evaporative Crystallization: Proof-of-Principle Application to Proteins. Crystal Growth \& Design 15, 3212-3219.

Mildažienè, V., Aleknavičiūtè, V., Žūkienė, R., Paužaitė, G., Naučienė, Z., Filatova, I., Lyushkevich, V., Haimi, P., Tamošiūnè, I., Baniulis, D., 2019. Treatment of Common Sunflower (Helianthus annus L.) Seeds with Radio-frequency Electromagnetic Field and Cold Plasma Induces Changes in Seed Phytohormone Balance, Seedling Development and Leaf Protein Expression. Sci Rep 9, 6437-6437. 
612 Mildaziene, V., Pauzaite, G., Malakauskiene, A., Zukiene, R., Nauciene, Z., Filatova, I., 613 Azharonok, V., Lyushkevich, V., 2016. Response of perennial woody plants to seed treatment by electromagnetic field and low-temperature plasma. Bioelectromagnetics 37 , 536-548.

Mohammed, M., Clement, T.C., Aslan, K., 2014. Circular Bioassay Platforms for Applications in Microwave-Accelerated Techniques. Nano Biomed Eng 6, 85-93.

Noble, R.E., 2002. Effects of UV-irradiation on seed germination. Science of The Total Environment 299, 173-176.

Oskooi, A.F., Roundy, D., Ibanescu, M., Bermel, P., Joannopoulos, J.D., Johnson, S.G., 2010. Meep: A flexible free-software package for electromagnetic simulations by the FDTD method. Computer Physics Communications 181, 687-702.

Perfecto, I., Vandermeer, J., 2010. The agroecological matrix as alternative to the landsparing/agriculture intensification model. Proceedings of the National Academy of Sciences $107,5786$.

Pinard, M.A., Aslan, K., 2010. Metal-Assisted and Microwave-Accelerated Evaporative Crystallization. Cryst Growth Des 10, 4706-4709.

Scott, S.E., Inbar, Y., Wirz, C.D., Brossard, D., Rozin, P., 2018. An Overview of Attitudes Toward Genetically Engineered Food. Annual Review of Nutrition 38, 459-479.

Thompson, N., Boone-Kukoyi, Z., Lansiquot, C., Toker, S., Kioko, B., Ajifa, H., Nwawulu, C., Daodu, O., Aslan, K., 2017. Metal-Assisted and Microwave-Accelerated Decrystallization: An Alternative Approach to Potential Treatment of Crystal Deposition Diseases. Clin Arch Bone Joint Dis 1, 1-13. 


\section{FIGURE LEGENDS}

660 Figure 1. The crux of the MAMAG technique: citrate-stabilized (negatively charged) gold 661 nanoparticles ( $\mathrm{Au}$ NPs) are accelerated by the electromagnetic field. The increased kinetic 662 energy of Au NPs increases collisions between nanoparticles and basil seeds. Seed testae develop 663 cracks and ridges due to collisions of Au NPs with the seed surface and resistive losses due to

664 microwave heating of water within the seeds, leading to controlled germination of seeds. 665 Esterase activity on the seed surface is also increased due to the presence of Au NPs and 666 microwave heating. Gold nanoparticles bind to the enzymes/proteins via Au-thiol and $667 \mathrm{Au}$ /primary amine bonds and electrostatic interactions. Wavelength of monomode 668 electromagnetic field at $8 \mathrm{GHz}$ is ca. $3.75 \mathrm{~cm}$.

670 Figure 2. Bright-field images of basil seeds before and after application of microwave heating.

671 Dry basil seeds, basil seeds in water (no Au NPs), or basil seeds in $20 \mathrm{~nm} \mathrm{Au} \mathrm{NPs} \mathrm{were}$ 672 microwaved at $2 \mathrm{~W}, 10 \mathrm{~W}$, and $20 \mathrm{~W}$ of microwave power. The presence of Au NPs and 
673 microwave heating causes the seeds to develop longer gum within 6 minutes. Each basil seed is

674 ca. $1.1 \mathrm{~mm}$ in length in the longest axis.

675

676 Figure 3. Scanning electron microscope images of basil seed gum after continuous microwave

677 heating $(2 \mathrm{~W}, 10 \mathrm{~W}$, or $20 \mathrm{~W})$ for 6 minutes. Control seeds were kept at room temperature for 6

678 minutes in either water or $20 \mathrm{~nm} \mathrm{Au} \mathrm{NPs} \mathrm{without} \mathrm{microwave} \mathrm{heating.} \mathrm{Basil} \mathrm{seed} \mathrm{gum} \mathrm{appears}$

679 more spread out due to microwave heating and $20 \mathrm{~nm} \mathrm{Au} \mathrm{NPs.} \mathrm{Circular} \mathrm{structures} \mathrm{seen} \mathrm{in} \mathrm{basil}$

680 in water is in $5 \mathrm{~mm}$ in size and part of the basil gum. Although Au NPs are significantly smaller

681 than these circular structures, Au NPs are brighter due to their ability to scatter light more

682 efficiently than the seed components. Scale bars $=50 \mathrm{~mm}$ and $5 \mathrm{~mm}$ (images on the right).

684 Figure 4. FDTD simulation of resistive losses from basil seeds fully immersed in water exposed

685 to monomode microwave point source operating at $8 \mathrm{GHz}$ and $10 \mathrm{~W}$ using COMSOL software.

686 Top and side view of the microwave cavity and seeds are shown on the left. Resistive losses

687 from the seeds are shown as slices starting from the layer bottom of the seeds up to the layer

688 corresponding to the plane on top of the seeds.

690 Figure 5. Basil seeds in hydroponic growth. Three basil seeds were kept in water without Au

691 NPs at room temperature (No MW/RT), or kept in a solution of $20 \mathrm{~nm} \mathrm{Au} \mathrm{NPs} \mathrm{at} \mathrm{room}$ 692 temperature, or microwave heated (MW) in in a solution of $20 \mathrm{~nm}$ Au NPs for 6 min at $10 \mathrm{~W}$ and 693 placed into a modified growth system. Basil seeds in water at room temperature (no microwave 694 heating) are used as a control sample to monitor the normal hydroponic growth.

696 Figure 6. Basil seed growth in soil in a greenhouse. Basil seeds were microwaved continuously 697 for 6 minutes at $2 \mathrm{~W}, 10 \mathrm{~W}$, and $20 \mathrm{~W}$. Basil seeds in water only (no microwave heating) and 698 basil seeds in $20 \mathrm{~nm}$ Au NPs only (no microwave) were used as control basil seeds. All pictures 699 were taken together with the same camera. Vertical white line shows the length of basil plants = $7007 \mathrm{~cm}$. 
The crux of metal-assisted and microwave-accelerated germination of seeds

\section{Before Microwave Heating}

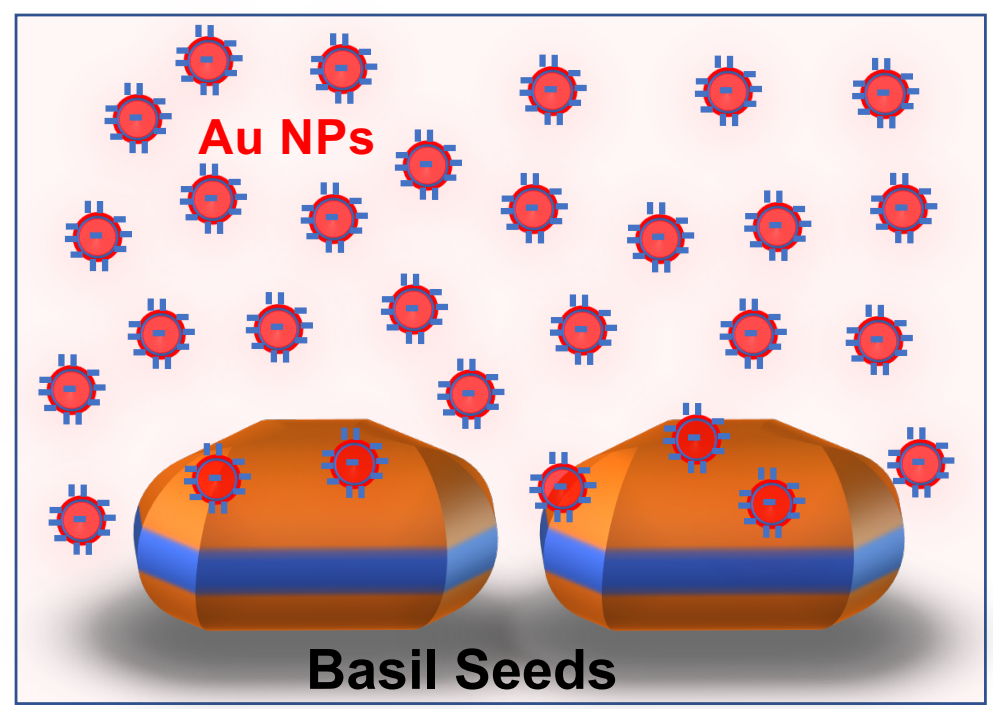

During / After Microwave Heating

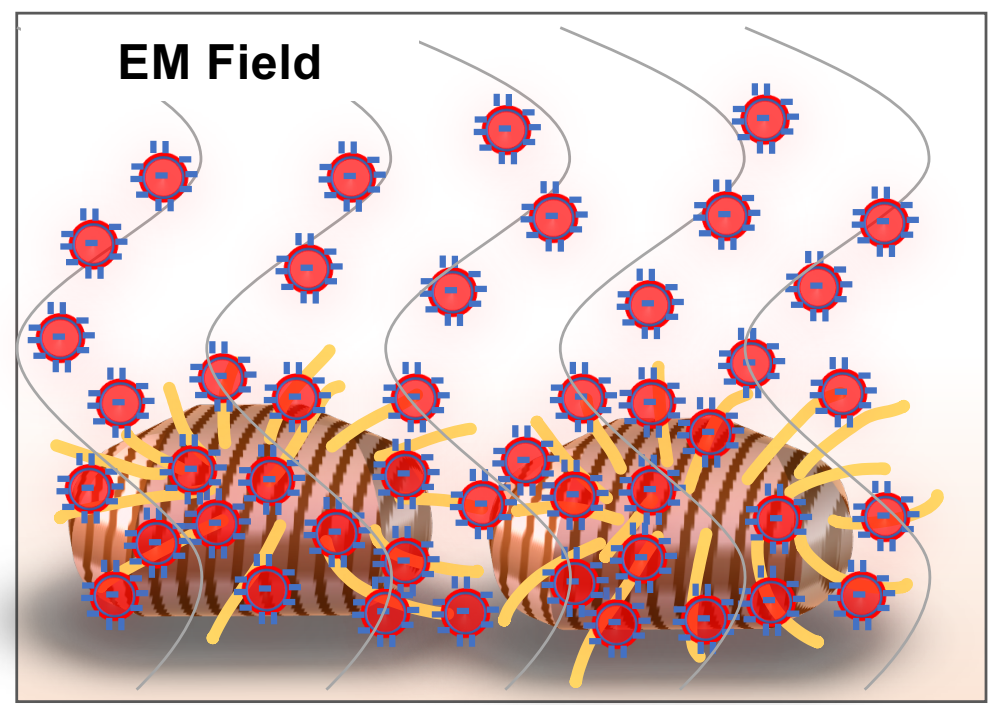

Figure 1. The crux of the MAMAG technique: citrate-stabilized (negatively charged) gold nanoparticles (Au NPs) are accelerated by the electromagnetic field. The increased kinetic energy of Au NPs increases collisions between nanoparticles and basil seeds. Seed testae develop cracks and ridges due to collisions of Au NPs with the seed surface and resistive losses due to microwave heating of water within the seeds, leading to controlled germination of seeds. Esterase activity on the seed surface is also increased due to the presence of Au NPs and microwave heating. Gold nanoparticles bind to the enzymes/proteins via Au-thiol and Au/primary amine bonds and electrostatic interactions. Wavelength of monomode electromagnetic field at $8 \mathrm{GHz}$ is ca. $3.75 \mathrm{~cm}$. 


\section{Optical images of basil seeds}

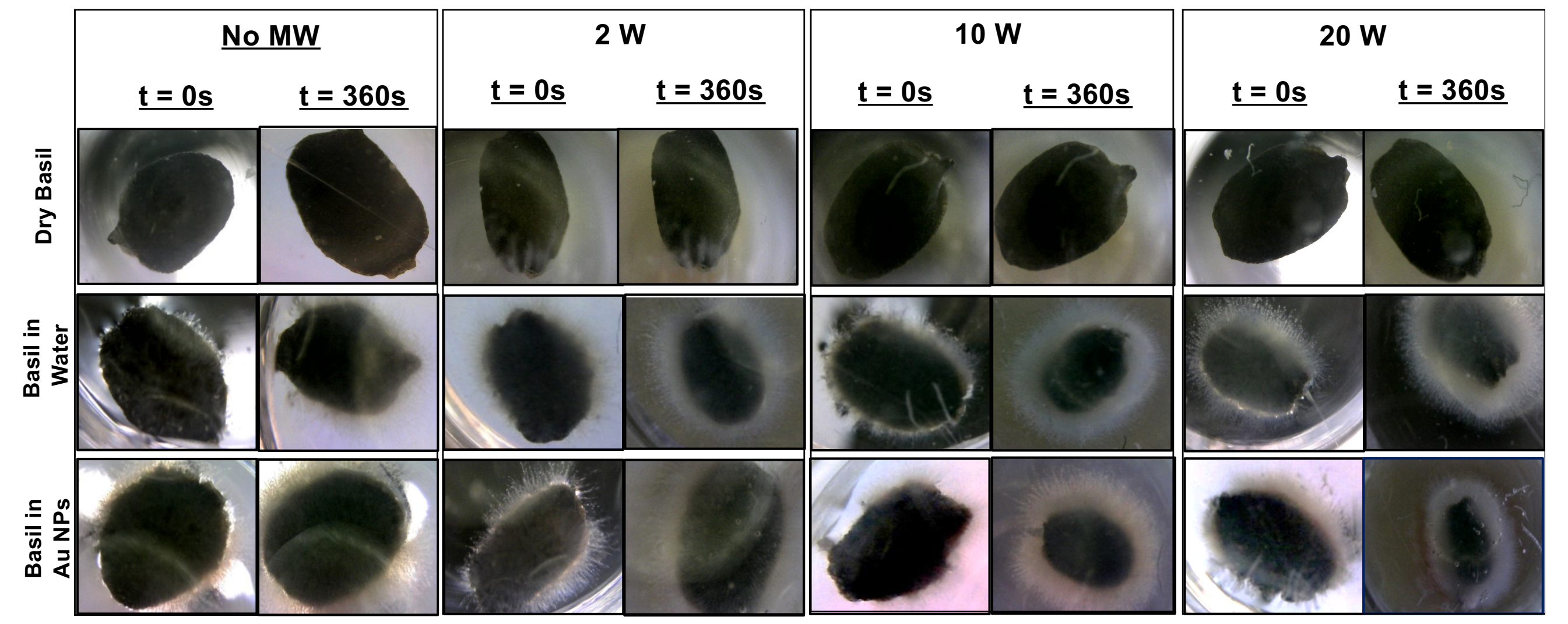

Figure 2. Bright-field images of basil seeds before and after application of microwave heating. Dry basil seeds, basil seeds in water (no Au NPs), or basil seeds in $20 \mathrm{~nm}$ Au NPs were microwaved at $2 \mathrm{~W}, 10 \mathrm{~W}$, and $20 \mathrm{~W}$ of microwave power. The presence of Au NPs and microwave heating causes the seeds to develop longer gum within 6 minutes. Each basil seed is ca. $1.1 \mathrm{~mm}$ in length in the longest axis. 
SEM images of basil seeds after 6 minutes

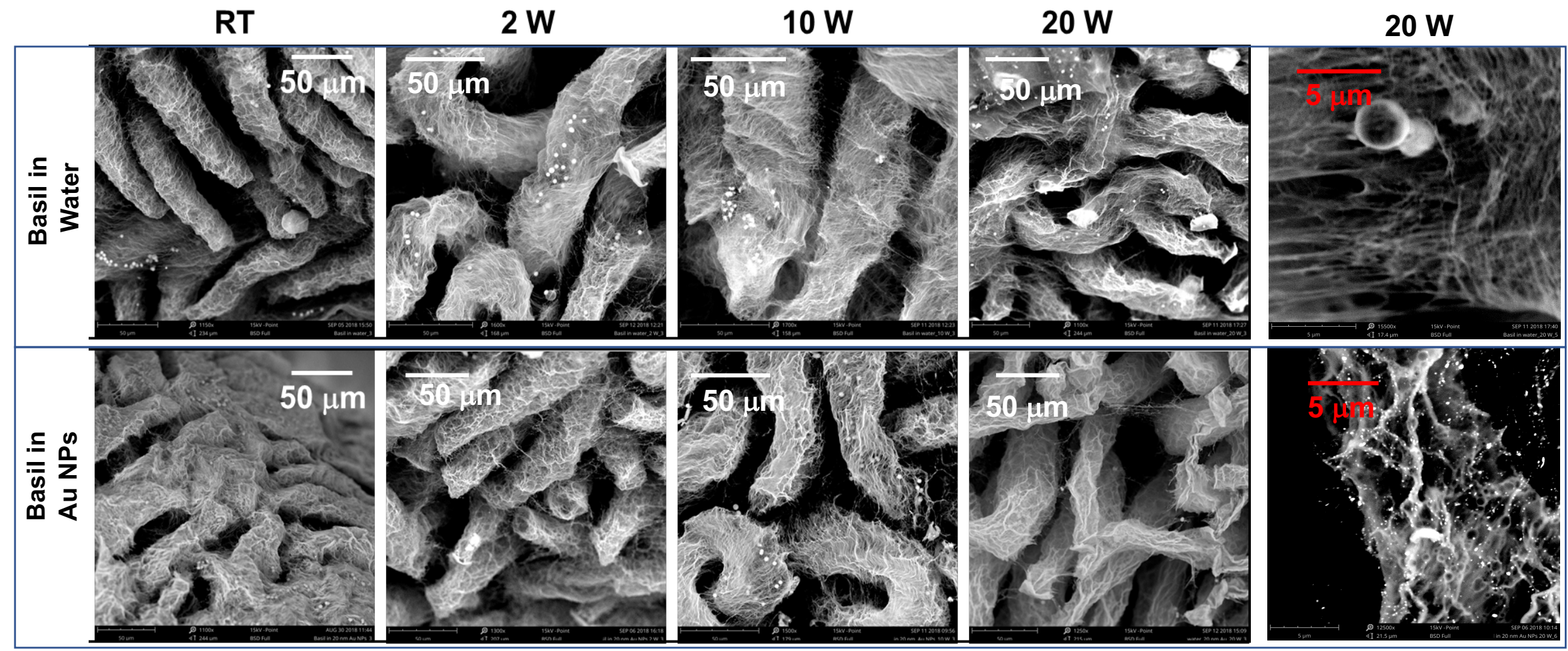

Figure 3. Scanning electron microscope images of basil seed gum after continuous microwave heating ( $2 \mathrm{~W}, 10 \mathrm{~W}$, or $20 \mathrm{~W})$ for 6 minutes. Control seeds were kept at room temperature for 6 minutes in either water or $20 \mathrm{~nm}$ Au NPs without microwave heating. Basil seed gum appears more spread out due to microwave heating and 20 $\mathrm{nm}$ Au NPs. Circular structures seen in basil in water is in $5 \mu \mathrm{m}$ in size and part of the basil gum. Although Au NPs are significantly smaller than these circular structures, $\mathrm{Au}$ NPs are brighter due to their ability to scatter light more efficiently than the seed components. Scale bars $=50 \mu \mathrm{m}$ and $5 \mu \mathrm{m}$ (images on the right). 


\section{Theoretical Simulations for Resistive Losses}

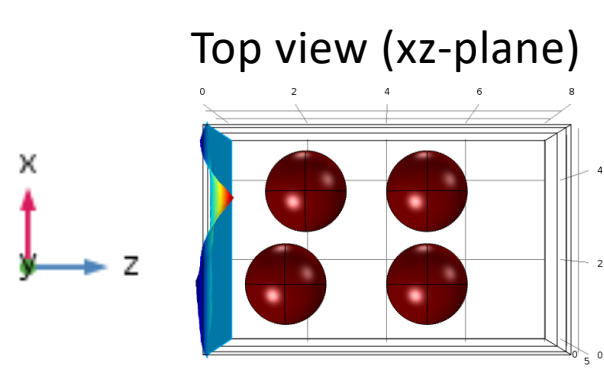

$\vdots$

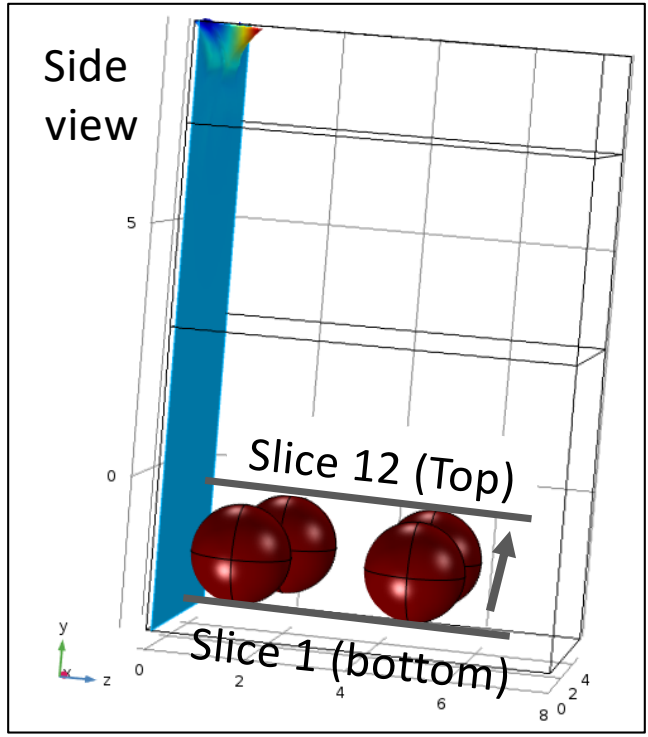

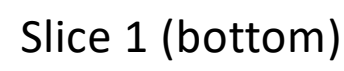

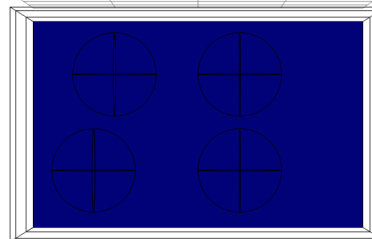

Slice 2

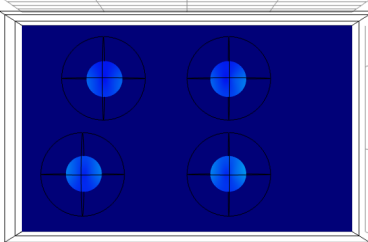

Slice 6

Slice 5

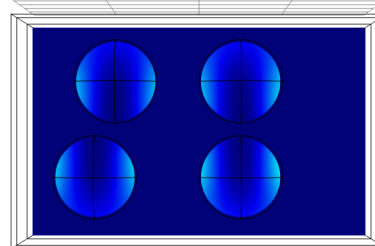

t.

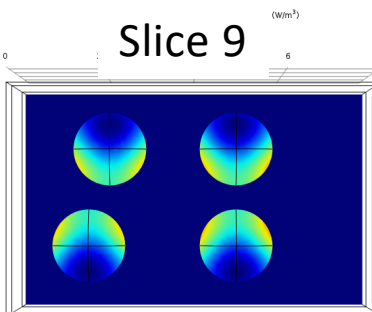

$\stackrel{x}{b}$

$\stackrel{x}{1}$

$\vdots$
Slice 3

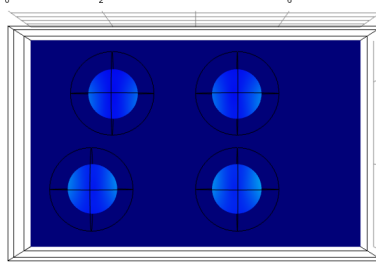

i.

Slice 7
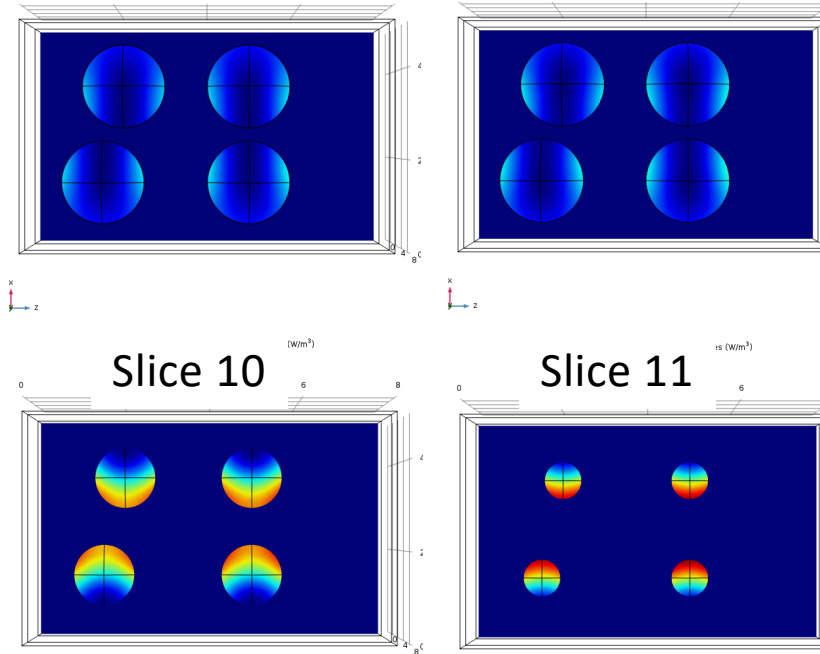

$\vdots$

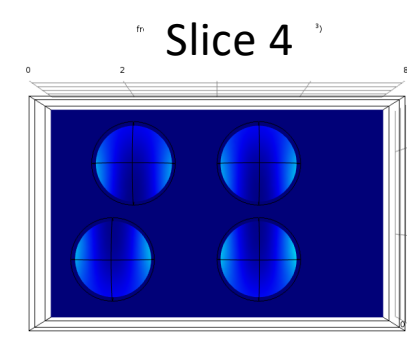

Slice 8

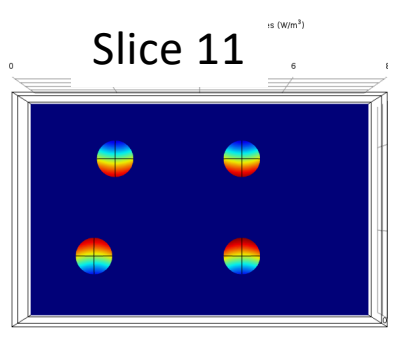

Slice 12 (Top)

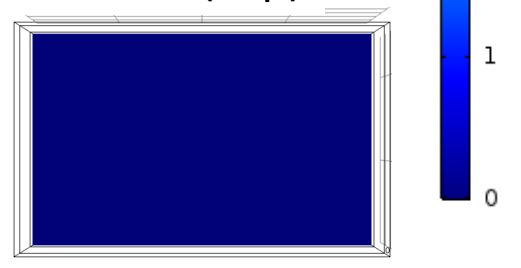

Freq $=8 \mathrm{GHz}$, Slice $=$ Resistive losses $\left(\mathrm{W} / \mathrm{m}^{3}\right)$

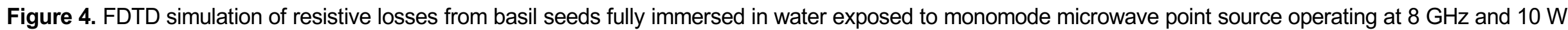

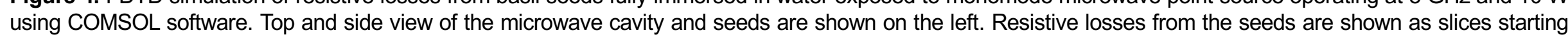
from the layer bottom of the seeds up to the layer corresponding to the plane on top of the seeds. 


\section{Basil Seed Hydroponic Growth}

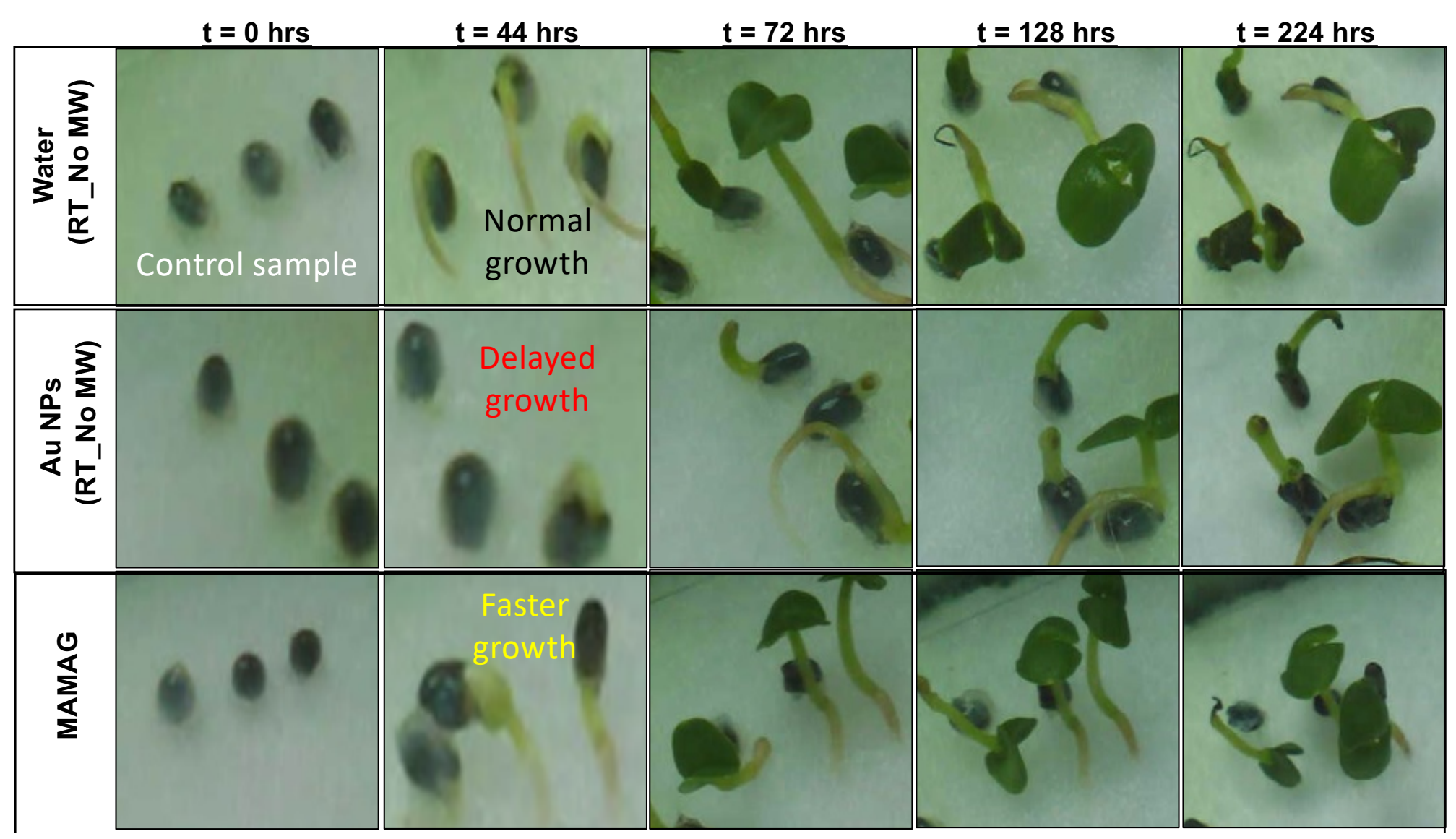

Figure 5. Basil seeds in hydroponic growth. Three basil seeds were kept in water without Au NPs at room temperature (No MW/RT), or kept in a solution of $20 \mathrm{~nm}$ Au NPs at room temperature, or microwave heated (MW) in in a solution of $20 \mathrm{~nm}$ Au NPs for 6 min at $10 \mathrm{~W}$ and placed into a modified growth system. Basil seeds in water at room temperature (no microwave heating) are used as a control sample to monitor the normal hydroponic growth. 


\section{Basil Seed Growth in Greenhouse}

5 Days after planting in soil

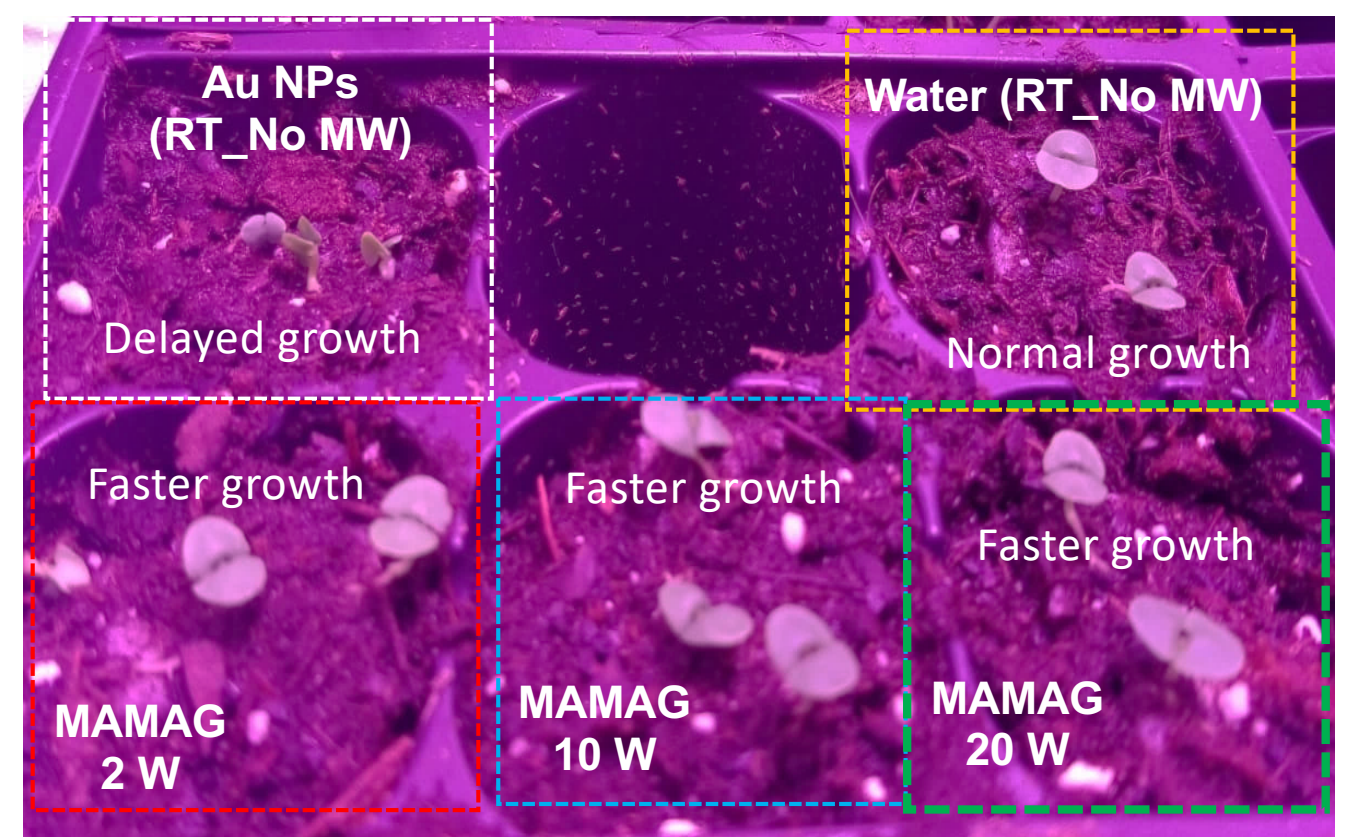

Figure 6. Basil seed growth in soil in a greenhouse. Basil seeds were microwaved continuously for 6 minutes at $2 \mathrm{~W}, 10 \mathrm{~W}$, and $20 \mathrm{~W}$. Basil seeds in water only (no microwave heating) and basil seeds in $20 \mathrm{~nm}$ Au NPs only (no microwave) were used as control basil seeds. All pictures were taken together with the same camera. Vertical white line shows the length of basil plants $=7 \mathrm{~cm}$.
73 Days after planting in soil

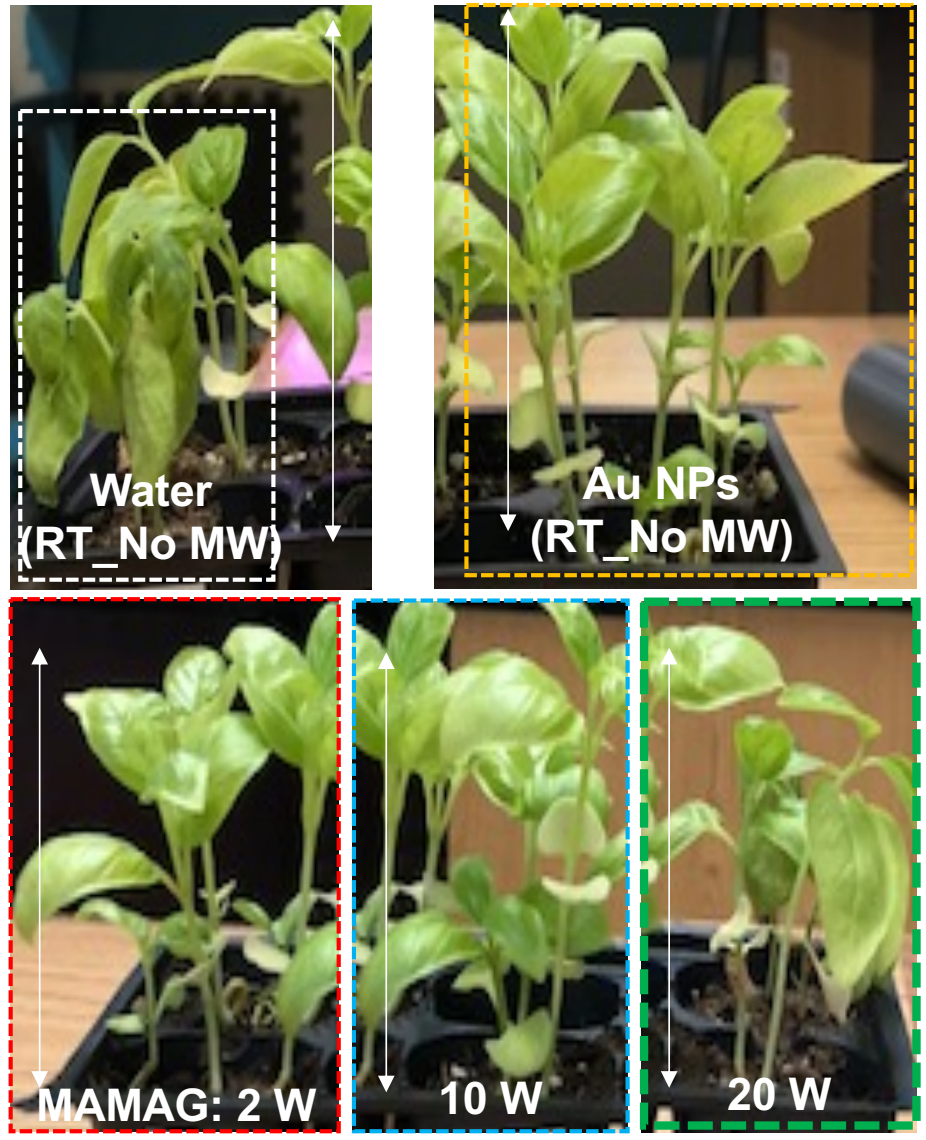


TOC

Before Microwave Heating

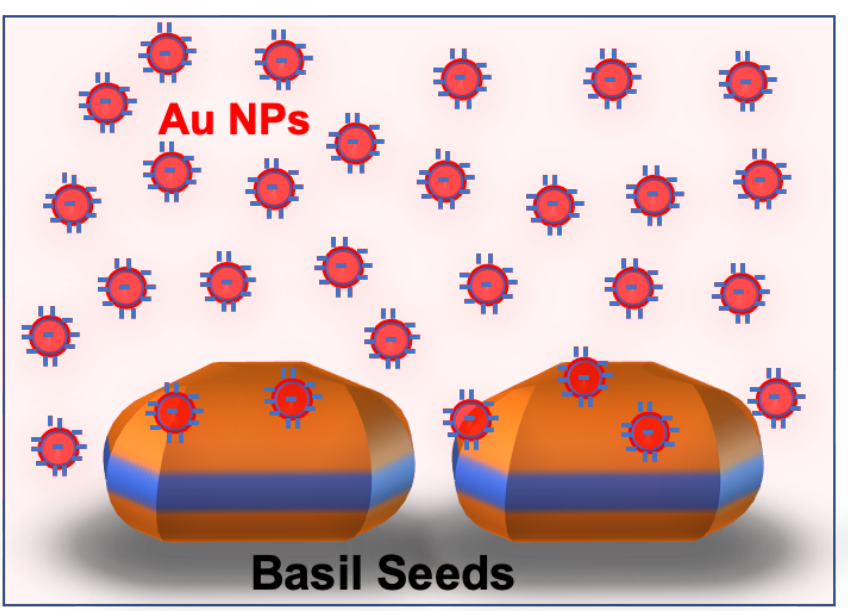

\section{During / After Microwave Heating}

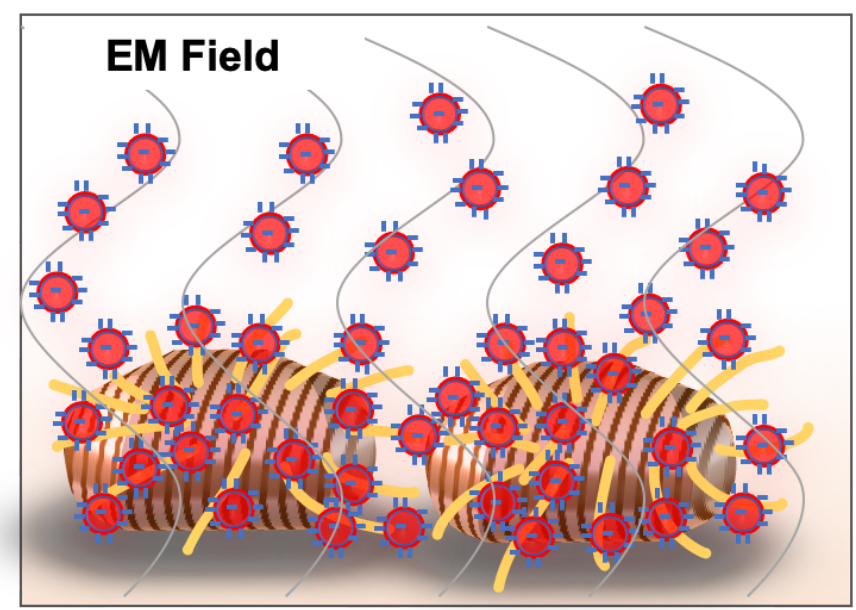

